\title{
Cardiovascular Manifestation in Patients with Hypothyroid Disorder in Bangladesh
}

Dr. Md. Daharul Islam ${ }^{*}$, Dr. khaleda Akter $^{2}$, Dr. Md. Emran Hossain ${ }^{3}$, Dr. Md. Sakhawat Hossain ${ }^{4}$, Dr. Muhammad Mahbub Hossain ${ }^{5}$

\footnotetext{
${ }^{1}$ Associate Professor, Department of Medicine, Sir Salimullah Medical College \& Mitford Hospital Dhaka, Bangladesh

${ }^{3}$ Assistant Professor, Department of Cardiology, Chattagram Medical College \& Hospital, Chattagram, Bangladesh

${ }^{2}$ Associate Professor Department of Gynae \& Obs, Z.H. Sikder Women's Medical College \& Hospital Dhaka, Bangladesh

${ }^{4,5}$ Assistant Professor, Department of Medicine, Sir Salimullah Medical College \& Mitford Hospital Dhaka, Bangladesh
}

DOI: $10.36347 /$ sjams.2021.v09i04.001

| Received: 06.03.2021 | Accepted: 28.03.2021 | Published: 02.04.2021

*Corresponding author: Dr. Md. Daharul Islam

\section{Abstract}

Original Research Article

Background: The cardiovascular symptoms of thyroid disease are some of the most penetrating and clinically pertinent findings of hypothyroidism. For coronary artery disease, hypothyroidism is a risk factor. However, a limited study conducted in our country to identifying cardiovascular manifestations of hypothyroid disorder. Aim of the study: The aim of the study was to address the clinical sign and symptoms of the hypothyroid disorder in Bangladesh. Materials and Methods: It was a descriptive cross-sectional study. The study was done in the Department of Medicine, Sir Salimulah Medical College \& Mitford Hospital, Dhaka from September 2017 to February 2018. A total of 70 patients were selected for the study. Statistical data were analyzed by SPSS 20.0 version. Results: The age of the patients with hypothyroidism ranged from 16-65 years. The mean age was $37.31 \pm 13.70$ years. In hypothyroid cases, the male and female ratio was 1:4.83. The commonest general symptom of hypothyroid cases in the present study was found to be weight gain $75.71 \%$ followed by fatigue $60 \%$, hoarseness of voice $51.42 \%$, and cold intolerance $50 \%$, and goiter $10 \%$. The commonest cardiovascular symptom of hypothyroid was found to be chest pain $32.85 \%$, followed by dyspnoea $30 \%$, ankle swelling $21 \%$. Clinical examination of the cardiovascular system of hypothyroid cases revealed diminished heart sound in $31.42 \%$ of patients, $30 \%$ of patients had bradycardia, diastolic hypertension was found in $22.85 \%$ cases and $21 \%$ of patients presented with pedal oedema. In the present study, the commonest EGG finding of hypothyroid patients was found to be sinus bradycardia 40\%, followed by low voltage EGG 35.71\%, non-specific ST$\mathrm{T} 27.14 \%$, RBBB 10\%, LBBB 5.71\%, and no heart block were found. The commonest abnormal echocardiography findings of hypothyroid patients were pericardial effusion $25.71 \%$, followed by systolic dysfunction $7.1 \%$, IVS thickness $7.1 \%$. Conclusion: According to this study of hypothyroidism was common in the third \& fourth decade of life. Females were more commonly affected than males. Since the patients with thyroid disease usually present with cardiovascular manifestation and cardiovascular manifestation may be the only manifestation of the hypothyroid disorder so it can recommend that all patients with a thyroid disorder should be searched for cardiovascular manifestation and a thyroid function test should be done in all patients with unexplained cardiovascular disease.

Key word: Patients, study, cardiovascular, hypothyroid, thyroid, manifestation, found, disease, hypothyroidism, disorder.

Copyright $\odot$ (C)21 The Author(s): This is an open-access article distributed under the terms of the Creative Commons Attribution 4.0 International License (CC BY-NC 4.0) which permits unrestricted use, distribution, and reproduction in any medium for non-commercial use provided the original author and source are credited.

\section{INTRODUCTION}

The cardiovascular symptoms of thyroid disease are some of the most penetrating and clinically pertinent findings of hypothyroidism. Hypothyroidism is distinct as a syndrome categorized by the clinical and biochemical indicators of thyroid hormone deficiency in the target tissues of the thyroid hormone [1]. Hypothyroidism denotes deficient thyroid gland production of thyroid hormone. This may be caused by an abnormality in the thyroid gland itself as primary hypothyroidism. Insufficient Thyroid Stimulating Hormone (TSH) stimulation of the thyroid gland which caused by an abnormality in the pituitary gland or hypothalamus (secondary Hypothyroidism) [1]. It has long been recognized that some of the most characteristic and common signs and symptoms of thyroid disease are those that result from the effects of thyroid hormone on the heart and cardiovascular system $[2,3]$. Hypothyroidism produce myocardial oxygen 
consumption, cardiac contractility, blood pressure, and systemic vascular resistance (SVR) $[4,5]$. Though it is less recognized that hypothyroidism can predispose to ventricular dysrhythmias[6] thyroid hormone is necessary for normal cardiovascular function, so when not enough thyroid hormone is present neither in the heart nor the blood vessels function normally [7]. In hypothyroidism, the heart muscle is weakened in both the contraction phase and also in relaxation phase [8]. This indicates that the heart cannot pump as forcefully as it should, and the amount of blood it ejects with each heartbeat is reduced [9]. In addition, because heart muscle does not relax normally in between heartbeats, diastolic dysfunction may result [10]. Bradycardia with low voltage $\mathrm{T}$ waves in the electrocardiogram is common in hypothyroidism but occasionally the rate may be normal, and instances of arrhythmias which resolve, somewhat paradoxically, by treatment with thyroxine, have been reported [11]. Thyroid heart disease including Paroxysmal rapid arrhythmias also occurs in patients with autoimmune thyroid disease [12]. Cardiac enlargements are usually the result of increased diastolic filling from bradycardia and, infrequently, caused by a large pericardium I effusion. Minor degrees of effusion are common but are only detectable by echocardiography [13]. Graettinger et al. [13] found no hemodynamic evidence of cardiac failure in this condition and these accords with the rarity of failure and the generally complete resolution of physical signs on adequate treatment with thyroxine. In the manner in which thyroid hormones affect the heart and circulation, considerable clinical variation exists. Generally, the non-cardiac element of the endocrine disorder will overshadow symptoms and signs, and little notice is taken of the cardiovascular status, which will return to normal once treatment of the thyroid condition is affected. For the older patients who are less likely to show evidence of thyroid disease, an entirely different situation is extant in though the underlying metabolic disturbance is still pronounced. Thyroid disease is the precipitating cause of arrhythmias, cardiac failure, and even angina pectoris may go unrecognized for many years before hyperthyroidism is diagnosed [14].The endocrine basis of the hitherto idiopathic nature of the cardiac condition, appropriate treatments then clearly indicate. It is claimed that recognition of subclinical hypothyroidism or 'premyxoedema' and treatment with thyroxine of this form may prevent progression to atherosclerotic disease [15].

\section{Materials \& Methods}

This is a descriptive cross-sectional study. The study was done in the Department of Medicine, Sir Salimulah Medical College \& Mitford Hospital, Dhaka, from September 2017 to February 2018. A total of 70 patients was selected for the study. Informed written consent was taken from the participants after a full explanation regarding the study. An ethical clearance certificate was taken from the concerned authorities of the institute. Patients with clinical symptoms of hypothyroidism were separated from the patients attending the general medicine OPD. They were afterward persistent a thyroid function test. The patient group comprised 70 individuals who were proven hypothyroid biochemically and with clinical symptoms. All the results were statistically analyzed by were taken by SPSS-20 version and MS-Excel-16.

\section{RESULT}

A total of 70 patients with thyroid disorder coming into the outpatient department or admitted to the Department of Medicine of Sir Salimullah Medical college hospital, Dhaka were included in this study. Most cases fell in the age group of 36-45 yrs. The mean age is 35 yrs. There was an overall female preponderance over all age groups with a mean age of 34.6yrs [Figure-1]. The female Population constituted $82.86 \%$ of the total but the male was found only $17.14 \%$ [Figure-2]. The commonest general symptom of hypothyroid cases in the present study was found to be weight gain $75.71 \%$ followed by fatigue $60 \%$, hoarseness of voice $51.42 \%$, and cold intolerance $50 \%$, and goiter $10 \%$ [Table-1]. The commonest cardiovascular symptom of hypothyroid cases in the present study was found to be thyroid chest pain $32.85 \%$, followed by dyspnoea $30 \%$, ankle swelling $21 \%$ [Table-2]. Clinical examination of the cardiovascular system of hypothyroid cases revealed diminished heart sound in $31.42 \%$ of patients, $30 \%$ of patients had bradycardia, systolic hypertension was found in $22.85 \%$ of patients, and $21 \%$ of patients presented with pedal edema [Table-3]. Total $7.14 \%$ of the patients of hypothyroid patient patients had cardiomegaly [Table-4]. In the present study the commonest EGG finding of hypothyroid patients was found to be sinus bradycardia $40 \%$, followed by low voltage EGG $35.71 \%$, non-specific ST-T $27.14 \%$, RBBB 10\%, LBBB 5.71\%, and no heart block were found [Table-5]. The commonest abnormal echocardiography findings of hypothyroid patients were pericardial effusion $25.71 \%$, followed by systolic dysfunction 7.1\%, IVS thickness $7.1 \%$ [Table-6]. Among the total 70 hypothyroid cases, 7(10\%) were subclinical hypothyroid rest 63(90\%) were overt hypothyroidism [Figure-3]. The most common causes of hypothyroidism were primary idiopathic hypothyroidism 46 patients $65.72 \%$, followed by Hashimoto's thyroiditis 14 patients 20\%, panhypopituitarism 4 patients $5.71 \%$, iatrogenic 4 patients $5.71 \%$ and graves' hypothyroidism 2 patients $2.86 \%$ [Table-7]. 


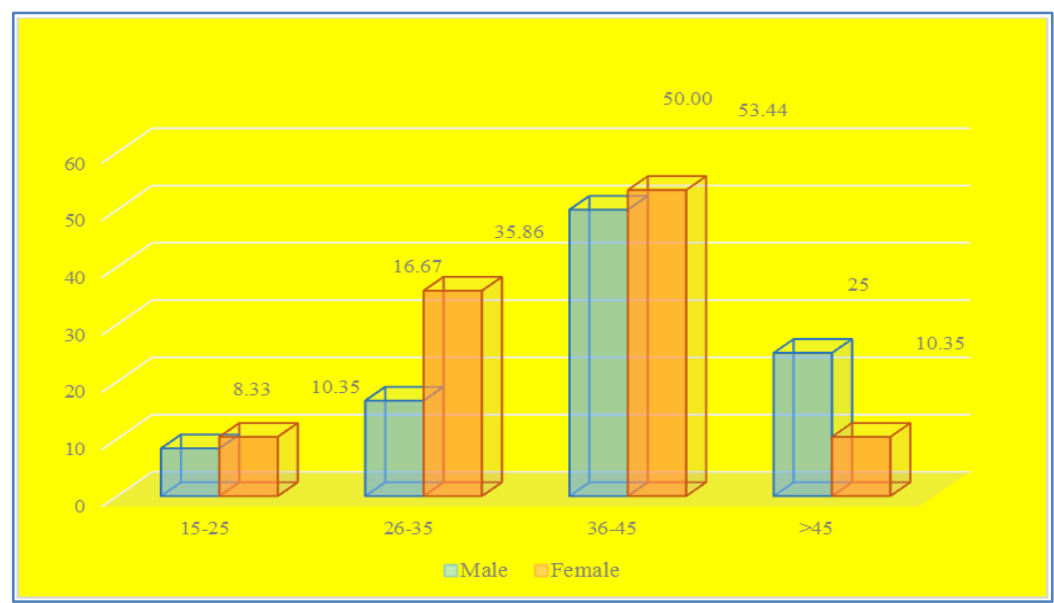

Fig-1: Age Distribution of hypothyroid cases $(\mathrm{N}=70)$

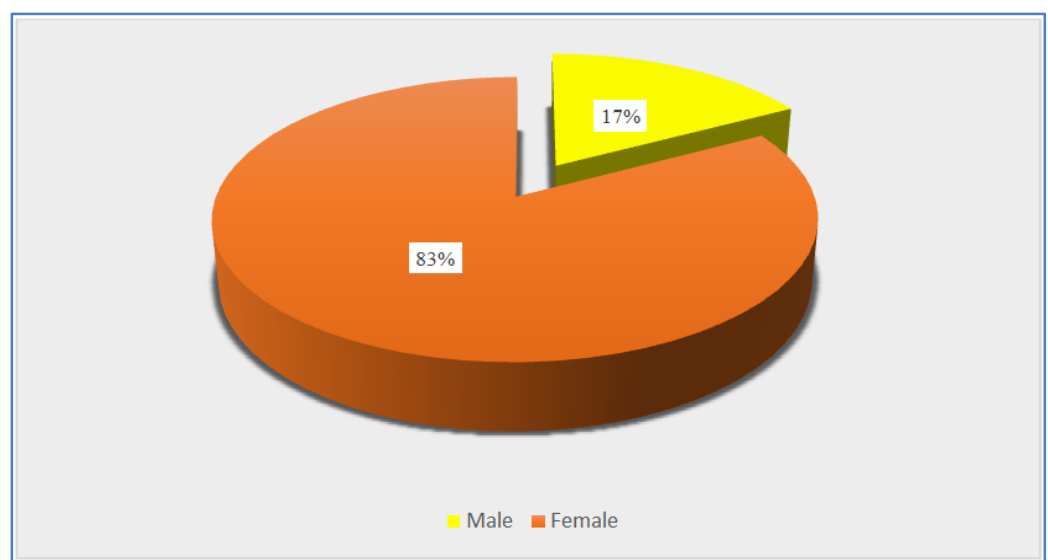

Fig-2: Gender wise distribution of hypothyroid cases $(\mathrm{N}=70)$

Table-1: Distribution of general symptoms of hypothyroid cases $(\mathbf{N}=70)$

\begin{tabular}{|l|l|l|l|}
\hline Symptoms & Male $(\mathbf{n = 1 2})$ & Female $(\mathbf{n}=\mathbf{5 8})$ & Total $(\mathbf{N}=\mathbf{7 0})$ \\
\hline Cold intolerance & $5(41.66)$ & $30(51.72)$ & $35(50.0)$ \\
\hline Weight gain & $11(91.66)$ & $42(72.41)$ & $53(75.71)$ \\
\hline Hoarseness of voice & $5(41.66)$ & $31(53.44)$ & $36(51.42)$ \\
\hline Goitre & $1(8.33)$ & $6(10.34)$ & $7(10.0)$ \\
\hline Fatigue & $7(58.33)$ & $35(60.34)$ & $42(60.0)$ \\
\hline Dyspnoea & $3(25.0)$ & $18(31.03)$ & $21(30.0)$ \\
\hline Chest pain & $4(33.33)$ & $19(32.75)$ & $23(32.85)$ \\
\hline Ankle swelling & $2(16.66)$ & $12(20.68)$ & $14(21.0)$ \\
\hline
\end{tabular}

Table-2: Distribution of cardiovascular symptoms of hypothyroid cases $(\mathrm{N}=70)$

\begin{tabular}{|l|l|l|l|}
\hline Symptoms & Male $(\mathbf{n = 1 2})$ & Female $(\mathbf{n = 5 8})$ & Total $(\mathbf{N}=\mathbf{7 0})$ \\
\hline Dyspnoea & $3(25.0)$ & $18(31.03)$ & $21(30.0)$ \\
\hline Chest pain & $4(33.33)$ & $19(32.75)$ & $23(32.85)$ \\
\hline Ankle swelling & $2(16.66)$ & $12(20.68)$ & $14(21.0)$ \\
\hline
\end{tabular}

Table-3: Distribution of cardiovascular signs of hypothyroid cases $(\mathrm{N}=70)$

\begin{tabular}{|l|l|l|l|}
\hline Signs & Male $(\mathrm{n}=12)$ & Female $(\mathrm{n}=58)$ & Total $(\mathrm{N}=70)$ \\
\hline Bradycardia & $4(33.33)$ & $7(29.33)$ & $21(30.0)$ \\
\hline Hypertension & $3(25.0)$ & $13(22.41)$ & $16(22.85)$ \\
\hline Pedal edema & $2(16.66)$ & $12(20.68)$ & $14(21.0)$ \\
\hline Diminished heart sound & $4(33.33)$ & $18(31.03)$ & $22(31.42)$ \\
\hline
\end{tabular}


Table-4: Distribution of $x$-ray findings of hypothyroid cases $(\mathrm{N}=70)$

\begin{tabular}{|l|l|l|l|}
\hline Chest X-ray findings & Male $(\mathbf{n = 1 2})$ & Female $(\mathbf{n}=\mathbf{5 8})$ & Total(N=70) \\
\hline Normal & $11(91.66)$ & $54(93.10)$ & $65(92.86)$ \\
\hline Cardiomegaly & $1(8.33)$ & $4(6.89)$ & $5(7.14)$ \\
\hline
\end{tabular}

Table-5: Distribution of ECG findings of hypothyroid cases $(\mathrm{N}=70)$

\begin{tabular}{|l|l|l|l|}
\hline ECG findings & Male $(\mathbf{n = 1 2})$ & Female $(\mathbf{n = 5 8})$ & Total $(\mathbf{N}=\mathbf{7 0})$ \\
\hline Low voltage ECG & $4(33.33)$ & $21(36.20 \%)$ & $25(35.71 \%)$ \\
\hline Brady arrhythmia including sinus bradycardia sinus arrest & $5(41.66)$ & $23(39.65)$ & $28(40.0)$ \\
\hline Heart block & $0(0.0)$ & $0(0.0)$ & $0(0.0)$ \\
\hline ST-T changes & $4(33.33)$ & $15(25.86)$ & $19(27.14)$ \\
\hline LBBB & $0(0.0)$ & $4(6.89)$ & $4(5.71)$ \\
\hline RBBB & $1(8.33 .0)$ & $6(10.34)$ & $7(10.0)$ \\
\hline
\end{tabular}

Table-6: Distribution of Echocardiography findings of hypothyroidism cases $(\mathrm{N}=70)$

\begin{tabular}{|l|l|l|l|}
\hline Echocardiography changes & Male $(\mathbf{n = 1 2})$ & Female $(\mathbf{n = 5 8})$ & Total $(\mathbf{N = 7 0})$ \\
\hline Systolic Dysfunction & $1(8.33)$ & $4(6.89)$ & $5(7.1)$ \\
\hline Pericardial effusion & $2(16.66)$ & $16(27.58)$ & $18(25.71)$ \\
\hline IVS thickness & $1(8.33)$ & $4(6.89)$ & $5(7.1)$ \\
\hline
\end{tabular}

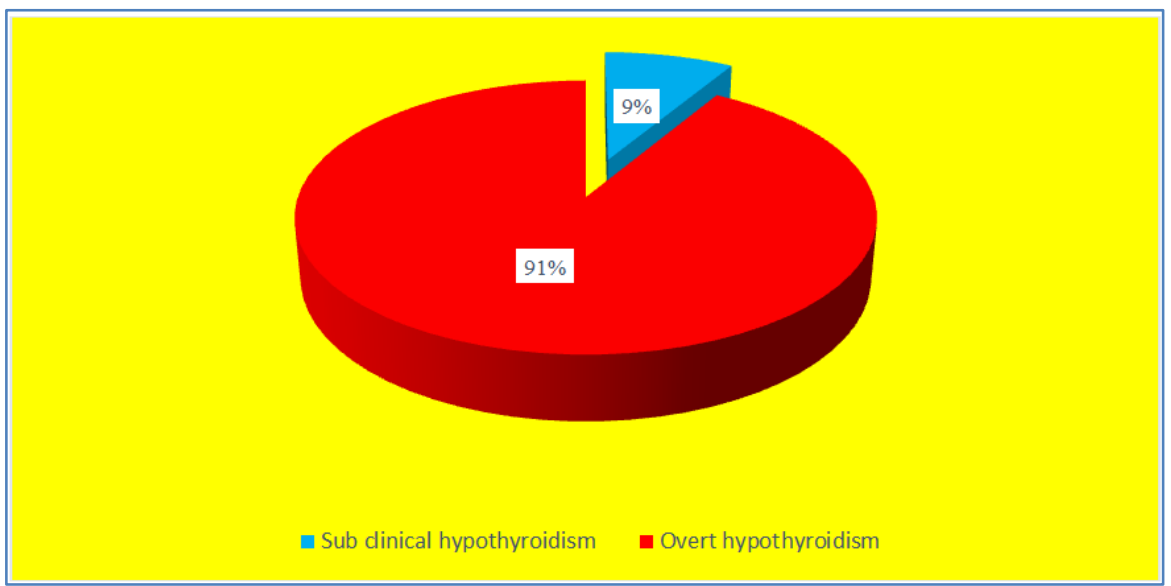

Fig-3: Distribution of sub clinical hypothyroidism and overt hypothyroidism $(\mathrm{N}=70)$

Table-7: Distribution of causes of hypothyroidism $(\mathrm{N}=70)$

\begin{tabular}{|l|l|l|}
\hline Causes of hypothyroidism & $\mathbf{n}$ & $\mathbf{\%}$ \\
\hline Primary idiopathic hypothyroidism & 46 & 65.72 \\
\hline Hashimoto's thyroiditis & 14 & 20 \\
\hline Graves' hypothyroidism & 2 & 2.86 \\
\hline Panhypopituitarism & 4 & 5.71 \\
\hline latrogenic & 4 & 5.71 \\
\hline Total & 70 & 100 \\
\hline
\end{tabular}

\section{DISCUSSION}

The heart is among the most responsive organ in thyroid disease, and cardiovascular symptoms and signs are therefore important clinical features of thyroid disorder [16]. Involvement of cardiovascular system in hypothyroid patients still provides some of the most common and conspicuous clue for diagnosis: Dyspnoea, chest pain, bradycardia, hypertension, diminished heart sound. The age of the patients with hypothyroidism was ranged from 16-65 years; the mean age was $37.31 \pm 13.70$ (Mean \pm SD) years. The highest number of patients was in the 36-45 years' group. Vishwanath [17] in India found a mean age of $35.5 \pm 4.47$ years. In 'Colorado [18] study' studies, the peak incidence of disease was in 35-44 years, which was almost similar to our population. In hypothyroid cases, the male and ratio were 1:4.83. Tunbridge et al. [19] and Vishwanath [20] found that ratios 2.68 and 3.75 respectively. In the Hunter study [21] female: a male was 5.4 which were almost similar to our population. The commonest general symptom of hypothyroid cases in the present study was weight gain $75.71 \%$ followed by fatigue $60 \%$, hoarseness of voice $51.42 \%$, cold intolerance $50 \%$, and goiter $10 \%$. Vishwanath [20] also found to be the commonest general symptom weight gain $73.3 \%$ 
followed by fatigue $66.6 \%$, hoarseness of voice $53.3 \%$, and cold intolerance $50 \%$, and goiter $10 \%$. The commonest cardiovascular symptom of hypothyroid cases in the present study was found to be chest pain $32.85 \%$, followed by dyspnoea $(30 \%)$, ankle swelling (21\%). Vishwanath [20] in his study found the most common symptom was to be dyspnoea (30\%) followed by ankle swelling (20\%). Clinical examination of the cardiovascular system of hypothyroid cases revealed diminished heart sound in $31.42 \%$ of patients, $30 \%$ of patients had bradycardia, diastolic hypertension was found in $22.85 \%$ of patients,s and $21 \%$ of patients presented with pedal oedema. Vishwanath [20] found diminished heart sound in $26.66 \%$ of patients, bradycardia in $40 \%$ of patients, and oedema in $20 \%$ of patients which can be considered as similar to our study. In the present study, the commonest ECG finding of hypothyroid patients was found to be sinus bradycardia $(40 \%)$, followed by Low voltage ECG (35.71\%), non-specific ST-T (27.14\%), RBBB (10\%), LBBB $(5.71 \%)$ and no heart block was found. Vishwanath20 "found sinus bradycardia (40\%) followed by Low voltage ECG (33.33\%), non-specific ST-T (26.66\%), RBBB (10\%), LBBB (6.66\%). The commonest abnormal echocardiography findings of hypothyroid patients were pericardiac Effusion (25.71\%), followed by systolic dysfunction $(7.1 \%)$, IVS thickness $(7.1 \%)$. Vishwanath [20] found pericardial effusion in $26.66 \%$ of patients followed by systolic dysfunction \& IVS thickness in $6.67 \%$ and $6.67 \%$ of patients respectively. In this study among the total 70 hypothyroid cases, 6(8.57\%) were subclinical hypothyroid, the rest of them $(91.43 \%)$ was overt hypothyroidism. Fatourechi [22] noted the incidence of subclinical hypothyroidism at 3 to $8 \%$ which was almost similar in our study. The most common causes of hypothyroidism were primary idiopathic hypothyroidism 46 patients $(65.72 \%)$, followed by Hashimoto's thyroiditis 14 patients (20\%), panhypopituitarism 4 patients $(5.71 \%)$, iatrogenic (postsurgery \& post radio ablation) 4 patients $(5.71 \%)$ and graves' hypothyroidism 2 patients $(2.86 \%)$. Hunter [21] found Hashimoto's thyroiditis $49 \%$, primary idiopathic hypothyroidism $25 \%$, and graves' hypothyroidism $9 \%$.

\section{Conclusion}

According to this study, hypothyroidism was common in the third \& fourth decade of life. Females were more commonly affected than males. The common cardiovascular manifestations of thyroid disorders were chest pain, dyspnea, bradycardia, and hypertension. Since the patients with thyroid disease usually present with cardiovascular manifestation and cardiovascular manifestation may be the only manifestation of the hypothyroid disorder so it can be recommended that all patients with a thyroid disorder should be searched for cardiovascular manifestation and a thyroid function test should be done.

\section{REFERENCE}

1. Wilmar M, Wiersinga, Hypothyroidism and myxoedemacoma, Endocrinology 4th Edition, 1: 1491- 92.

2. Dillmann WH. Cellular action of thyroid hormone on the heart. Thyroid. 2002; 12:447- 452.

3. Kahaly GJ, Dillmann WH. Thyroid hormone action in the heart. Endocrine Rev. 2005; 26:704 -728.

4. Biondi B, Palmieri EA, Lombard! G, Fazio S. Effects of thyroid hormone on cardiac function: the relative importance of heart rate, loading conditions, and myocardial contractility in the regulation of cardiac performance in human hyperthyroidism. J Clin Endocrinol Metab. 2002:87:968-974.

5. Klein I. Endocrine disorders and cardiovascular disease. In: Zipes DP, Libby P, Bonow R, Braunwald E, eds. Braunwald's Heart Disease: A Textbook of Cardiovascular Medicine. 7th ed. Philadelphia, Pa. W.B. Saunders; 2005:2051-2065.

6. Kroetz FW, De Groot WJ, Leonard JJ and Warren JV. Relationship of oxygen consumption to hemodynamic response in hypermetabolic states (abstract). Clinical Research Proceedings. 1962; 10.

7. Ben gel FM. Effect of thyroid hormones on cardiac function, J Clin Endocrinol Metab. 2000: 85: 1822 $-1827$.

8. Gonzalez Vilchoz F. Cardiac manifestations of primary hypothyroidism, Rev Es Cardiol. 1998; 51: $893-900$.

9. Iervasi G. Association between increased mortality and mild thyroid dysfunction in cardiac patients. ACH intern Med 167, 1526 - 1532.

10. Klein I, Thyroid hormone and the cardiovascular system, Am J Med. 1990; 88: 631-637.

11. Symons C, Myers A, Kingstone D and Boss M. Response to thyrotrophin releasing hormone in atriaI dysrhythmias. Postgraduate Medical Journal. 1978; 54, 658-662.

12. Kerber RE and Sherman B. Echocardiographic evaluation of pericardial effusion in myxedema. Circulation. 1975; 52: 823-827.

13. Graettinger JS, Muenster JJ, Checchia CS, Grissom RL and Campbell JA. Correlation of clinical and hemodynamic studies in patients with hypothyroidism. Journal of Clinical Investigation. 1958; 37, 502-510.

14. Fowler PBS, Swale $J$ and Andrews $H$. Hypercholesterolemia in borderline hypothyroidism. Lancet. 1970; 2,488-491.

15. Resnekov L and Falicov RE. Thyrotoxicosis and lactate-producing angina pectoris with normal coronary arteries. British Hearts Journal. 1937; 39: 1051-1057.

16. William GH Braun Wald E. Endocrine and Nutritional disorder of heart disease. In: Braun Wald E, ed. Heart Diseases text book of cardiovascular medicine, $8^{\text {th }}$ Edition, Philadelphia. W.B Saunders. 2007; 1827-1855 
Daharul Islam et al; Sch J App Med Sci, Apr, 2021; 9(4): 500-505

17. Hunter I, Greene S, MacDonald T, A. Morris. Prevalence and aetiology of hypothyroidism in the young, Arch Dis Child. 2000 September; 83(3): 207-210.

18. Resnekov L and Falicov RE. Thyrotoxicosis and lactate-producing angina pectoris with normal coronary arteries. British Hearts Journal. 1977; 39:1051-1057.

19. Tunbridge WMG, Evered DC, Hall R. The spectrum of thyroid disease in a community: The Whickham survey. Clin Endocrinol (Oxf). 1977; 7:481-493
20. Vishwanath BL. Cross Sectional Study of Cardiovascular Manifestations of Hypothyroidism. Thesis (M.D.). Rajiv Gandhi University of Health Sciences, Bangalore, Karnataka; 2008.

21. Hunter I, Greene S, MacDonald TA. Morris. Prevalence and aetiology of hypothyroidism in the young, Arch Dis Child. 2000 September; 83(3): 207-210.

22. Fatourechi V. Subclinical Hypothyroidism: An Update for Primary Care Physicians, Mayo Clin Proc. 2009 January; 84(1): 65-71. 